\title{
Influencia del estrés oxidativo seminal en el resultado de técnicas de fertilización in vitro
}

\author{
Influence of seminal oxidative stress in the results \\ of In Vitro Fertilization techniques
}

\author{
Ana María Iraizoz Barrios \\ Universidad Técnica de Machala, Machala \\ (Ecuador) \\ airaizoz@utmachala.edu.ec \\ Yohandra Crespo Ferrá \\ Hospital Clínico Quirúrgico \\ Hermanos Ameijeiras \\ (Cuba) \\ Olga Sonia León Fernández \\ Instituto de Farmacia y Alimentos - UH \\ (Cuba) \\ Germán Brito Sosa \\ Hospital Teófilo Dávila \\ (Ecuador) \\ Liván Delgado Roche \\ Universidad Autónoma de Ciudad Juárez \\ (México) \\ Rosa María Flores Sánchez \\ Hospital Clínico Quirúrgico \\ Hermanos Ameijeiras \\ (Cuba) \\ Elida Reyes Rueda \\ Universidad Técnica de Machala, Machala \\ (Ecuador)
}

Revista Cumbres Vol.3 №2

Versión impresa ISSN 1390-9541

Versión electrónica ISSN 1390-3365

http://investigacion.utmachala.edu.ec/revistas/index.php/Cumbres 


\title{
RESUMEN
}

Objetivo: Evaluar el estado redox en semen de hombres normozoospérmicos y en medios de cultivo embrionarios humanos, y su relación con el éxito de las técnicas de Fertilización In Vitro (FIV).Material y Método: Se aplicó una batería de marcadores de daño a biomoléculas, enzimas e indicadores globales del estado redox a muestras de plasma seminal, lisado de espermatozoides, así como a medios de cultivo embrionarios de 24 y 72 horas para valorar su relación con el éxito de las técnicas de Fertilización In Vitro. Las muestras de semen procedían de 15 pacientes normozoospérmicos a cuyas parejas se les aplicaron técnicas de Fertilización In Vitro. Resultados: Se confirmó que en todas las muestras analizadas los indicadores de daño a biomoléculas [malonindialdehído (MDA) y productos avanzados de la oxidación de proteínas $(P A O P)]$, se encontraban significativamente incrementados $(p<0,05)$ en los pacientes con respecto al grupo control, por lo que presentaban estrés oxidativo. Encontramos correlación entre los productos avanzados de la oxidación de proteínas (PAOP) en lisado de espermatozoides y medio de cultivo embrionario de 24 horas observándose una asociación directa y significativa $(p<0,05)$. Todo ello sugiere que los pacientes normozoospérmicos que concurren a las consultas de FIV presentan alteraciones de la capacidad fecundante por estrés oxidativo, y que, existe desbalance redox en los medios de cultivo embrionario que pudiera estar relacionado con el factor masculino.

Palabras clave: Estrés Oxidativo, Especies Reactivas del Oxígeno, Infertilidad Masculina, Medios de Cultivo Embrionarios, Fertilización In Vitro.

\begin{abstract}
Objective: To evaluate the redox status in the semen of normozoospermic men and in human embryonic culture media, as well as its relationship with the success of In Vitro Fertilization (IVF) techniques. Materials and Methods: A battery of damage indicators to biomolecules, enzymes, and global indicators of redox status was applied to seminal plasma samples, sperm lysate, as well as embryonic culture media of 24 and 72 hours to assess their relationship with the success of In Vitro Fertilization techniques. The semen samples came from 15 normozoospermic patients whose couples underwent in vitro fertilization techniques. Results: It was confirmed that in all the analyzed samples the indicators of damage to biomolecules [malonindialdehyde (MDA) and advanced products of protein oxidation (PAOP)] increased significantly $(p<0.05)$ in patients with respect to the control group, because they presented oxidative stress. We found correlation between the advanced products of protein oxidation (PAOP) in sperm lysate and 24-hour embryo culture media, showing a direct and significant association $(\mathrm{p}<0.05)$. All this suggests that normozoospermic patients attending IVF consultations present alterations in the fertilizing capacity due to oxidative stress, and that there is a redox imbalance in embryonic culture media that could be related to the male factor.
\end{abstract}


Keywords: Oxidative Stress, Reactive Species of Oxygen, Male Infertility, Embryonic Culture Media, In Vitro Fertilization.

\section{INTRODUCCIÓN}

Las especies reactivas del oxígeno (ERO) son compuestos químicos altamente inestables derivados del oxígeno que tienen tendencia a reaccionar con otras moléculas de su entorno a las que modifican oxidativamente, con lo cual pueden afectar su estructura y función. Entre las ERO son de especial interés los radicales libres (RL), que son especies químicas que poseen un electrón no pareado en su orbital más externo y se comportan como moléculas altamente reactivas. (Mallok, Martínez, Flores, \& Alonso, 2011) En un organismo saludable, las ERO y los antioxidantes permanecen en equilibrio. Cuando el equilibrio se rompe hacia una sobreproducción de ERO, o no funcionan adecuadamente los mecanismos antioxidantes, ocurre el estrés oxidativo (EO) lo cual conduce a daño celular. (Mallok, et al., 2011) (Agarwal, Said, Bedaiwy, Banerjee, \& Alvarez, 2006)

Entre las patologías donde ha sido estudiado el daño causado por estrés oxidativo, se encuentra la infertilidad masculina. (Agarwal, Gupta, \& Sharma, 2005) (Tremellen, 2008). Los espermatozoides requieren de cantidades pequeñas de ERO para comenzar la capacitación, así como la reacción acrosomal y fusión con la membrana del ovocito durante la fertilización, sin embargo, cuando ese ambiente es alterado se presentan cambios en su capacidad para fecundar. (Tremellen, Miari, Froiland, \& Thompson, 2007) Ellos son particularmente susceptibles al daño inducido por el estrés oxidativo debido al alto volumen de ácidos grasos polinsaturados en sus membranas. Como consecuencia de este desequilibrio, los lipoperóxidos generados inhiben la capacidad fertilizante de los espermatozoides. (Tremellen, et al, 2007) (Paparella, Pavesi, Feldman, \& Bouvet, 2015) Hay estudios que sugieren que entre un $30 \%$ y un $80 \%$ de los hombres infecundos presentan Estrés Oxidativo. (De Jonge, 2005)

Tradicionalmente, el diagnóstico de esterilidad masculina se ha basado en el ensayo convencional del semen. Este incluye información sobre volumen, concentración espermática, motilidad y morfología entre otras variables, que dan la evaluación aproximada de la competencia funcional de los espermatozoides, pero no siempre hace reflejo de la calidad de esperma ni del ADN espermático. (Nicolich, Lafuente, López, García-Peiró, \& Brassesco, 2013) Los hombres con los espermogramas normales todavía pueden ser infértiles, pero aún el estudio del estado redox de los pacientes infértiles sigue siendo controversial y polémico, y no se aplica de manera convencional en este análisis. (Gallardo- Montoya, 2007)

Si bien se han creado medios de cultivo embrionarios más favorables con características que simulan las condiciones de la trompa de Falopio in vivo, aún no se logra este objetivo, y son mayores cada vez los estudios que plantean que tanto los componentes de los medios de cultivos como la presencia de ERO, ya sea secretados por los gametos y/o el embrión o por el medio 
como tal, están influyendo de un modo determinante en que las tasas de embarazo de FIV se mantengan a un nivel tan bajo a nivel mundial (30-40\%).( Alba, Monzón, Peláez, \& Quintero, 2000)

Todo lo anterior hace que sea de suma importancia la investigación sobre los efectos de estas sobre los gametos y en los medios de cultivos donde se incuban tanto los gametos como los embriones, por lo que este trabajo pretende evaluar el estado redox en semen de hombres normozoospérmicos y en medios de cultivo embrionarios humanos, y su relación con el éxito de las técnicas de Fertilización In Vitro. (Agarwal, Cocuzza, Abdelrazik \&, Sharma, 2008).

\section{MATERIALES Y MÉTODOS}

Se trata de un estudio experimental, prospectivo, observacional, analítico, con control histórico de pacientes normozoospérmicos cuyas parejas fueron sometidas a fecundación in vitro, todas en un mismo ciclo de FIV en el servicio de Endocrinología y Reproducción Asistida del Hospital Clínico Quirúrgico Hermanos Ameijeiras, La Habana, Cuba.

Fueron incluidos los pacientes masculinos de las 15 parejas que concurrieron a realizarse procedimientos de FIV en el Hospital Clínico Quirúrgico Hermanos Ameijeiras en el período de tiempo de febrero a julio del 2012 que cumplían con los criterios de inclusión: parejas que el hombre presente espermograma normal y cuyas mujeres sean menores de 40 años con infertilidad de causa tubárica y que consintieron por escrito participar en el estudio luego de ser informados de las características de la investigación. Se tomaron un número igual de muestras de sujetos aparentemente sanos con fertilidad comprobada, que se utilizaron como referencias para el estudio del factor masculino. La edad y etnia del grupo control fueron similares a la del grupo en estudio.

Como criterios de exclusión se tuvieron en cuenta los pacientes que presentaron espermogramas con resultados patológicos, con alguna enfermedad infectocontagiosa, portadores de enfermedades crónicas no transmisibles cuya fisiopatología haya sido relacionada con desbalance redox (Diabetes Mellitus, Enfermedades Autoinmunes, Insuficiencias Vasculares, Cáncer e Hipertiroidismo), o con medicación a base de: Inhibidores de la monoamino oxidasa (IMAO), Antinflamatorios no esteroideos (AINES), Vitaminas Antioxidantes ( $\mathrm{C}$ y E), así como la participación en otro ensayo clínico o tratamiento con algún fármaco en fase experimental.

\section{Obtención de las muestras}

Obtención de las muestras de semen: Las muestras de semen fueron obtenidas por masturbación sin el empleo de algún de lubricante y con cuatro días de abstinencia eyaculatoria y se analizaron en la primera hora de la colección. En todos los pacientes, se realizó espermograma, según los criterios de la OMS del 2010. El resto de la muestra fue centrifugado a $800 \mathrm{~g} / \mathrm{min} \mathrm{x}$ 10 minutos, decantándose el sobrenadante en una alícuota e identificándose 
adecuadamente para estudio del líquido seminal. Fue guardado el líquido seminal congelado a $-20^{\circ} \mathrm{C}$ hasta su análisis. Para realizar estudio del lisado de espermatozoides al sedimento se le adicionó $1.5 \mathrm{ml}$ de solución de cloruro de sodio $0,9 \%$, fue centrifugado a $800 \mathrm{~g} / \mathrm{min}$ x 10 minutos y desechado el sobrenadante. Las células del sedimento fueron resuspendidas en $1.5 \mathrm{ml}$ de agua desionizada (agua para inyecciones) para lisarlas por shock osmótico y congeladas a $-20^{\circ} \mathrm{C}$ hasta su análisis.

Obtención de las muestras de medios de cultivo: Las muestras fueron incubadas en IVF Medicult, a $37^{\circ} \mathrm{C}$ con atmósfera de $5 \%$ de $\mathrm{CO}_{2}$ donde se depositó primero el ovocito en incubación durante 4 horas, luego se le adicionó los espermatozoides recuperados tras Test de Recuperación Espermática por gradiente de centrifugación para la fecundación. Los cultivos se cambian cada 24 horas hasta que los embriones son transferidos. La muestra, $500 \mu l$ de medio de cultivo se recogió a las 24 y 72 horas tras el cambio del cigoto o embrión al nuevo medio, siendo centrifugada a $800 \mathrm{~g} \mathrm{x} 10$ min para eliminar restos celulares. Luego se le aspiró el sobrenadante el cual fue alicuotado, identificado y guardado en congelación a $-20^{\circ} \mathrm{C}$ hasta su análisis. El sedimento fue desechado. Para las determinaciones bioquímicas se utilizaron los reactivos que se refieren en los procedimientos normalizados de operación (PNO) del laboratorio de bioquímica del CEIEB (de las firmas SIGMA o Merck). Todos los parámetros bioquímicos fueron determinados a través de técnicas espectrofotométricas con la utilización de un espectrofotómetro pharmacia 1000 (pharmacia lkb, uppsala, suiza) y un lector de placas suma (centro de inmunoensayos, La Habana, Cuba).

En este estudio se determinaron los marcadores de daño EO: Malonildialdehído (MDA), Hidroperóxidos totales (ROOH), y Productos avanzados de la oxidación de proteínas (PAOP), además de las Proteínas totales (PT) en muestras de líquido seminal y lisado de espermatozoides de pacientes y controles, así como en medio de cultivo de 24 y 72 horas.

\section{Determinación de MDA:}

El MDA se midió como indicador de la peroxidación lipídica, utilizando el método colorimétrico que emplea el 1-metil-2-fenil indol como cromógeno. Se leyó la absorbancia a $586 \mathrm{~nm}$ contra blanco reactivo. Se utilizó una curva patrón de 1, 1, 3,3-tetraetoxipropano para calcular las concentraciones finales. (Mallok, et al., 2011)

\section{Determinación de ROOH:}

Los peróxidos orgánicos y el $\mathrm{H}_{2} \mathrm{O}_{2}$, presentes en la muestra convierten el $\mathrm{Fe}^{2+}$ en $\mathrm{Fe}^{3+}$ en medio ácido. $\mathrm{El} \mathrm{Fe}^{3+}$ forma un complejo coloreado con el xilenol naranja que es detectable por medición espectrofotométrica a $560 \mathrm{~nm}$. (Delgado, 2012)

\section{Determinación de PAOP:}

Se determinó siguiendo la transformación de los iones yodo a yodo diatómico 
que provocan los PAOP siguiendo el cambio de D.O. a 340 nm. Se utilizó como patrón la cloramina $\mathrm{T}$ y los resultados se expresaron como $\mu \mathrm{M}$ de cloramina $\mathrm{T}$.

\section{Determinación de PT:}

Esta técnica se basó en una reacción de coloración entre las proteínas del medio y el reactivo Azul de Coommasie, el producto de esta reacción es detectable espectrofotométricamente y tiene un máximo de Absorción a una longitud de onda de $595 \mathrm{~nm}$. Esta técnica es válida para la detección de las proteínas que se encuentren en un intervalo de 0,01-0,05 mg.

\section{RESULTADOS Y DISCUSIÓN}

Durante el período estudiado fueron analizadas las muestras de medio de cultivo de 24 horas y 72 horas, y muestras de semen de 15 hombres que cumplieron con los criterios de inclusión planteados.

Al cuantificarse los indicadores de daño en Líquido seminal (Tabla 1), los indicadores del daño redox mostraron diferencias significativas $(p<0,05)$ entre pacientes y controles.

Tabla 1. Indicadores del daño redox en Líquido Seminal

\begin{tabular}{|c|c|c|c|c|}
\hline \multicolumn{2}{|c|}{ Biomarcador } & Controles & $\begin{array}{l}\text { Pacientes en es- } \\
\text { tudio }\end{array}$ & $\begin{array}{l}\text { Test de U de } \\
\text { Mann-Whitney }\end{array}$ \\
\hline \multirow{3}{*}{ Daño } & $\mathrm{MDA} *$ & $1,47 \pm 0,85$ & $10,27 \pm 4,70$ & $\mathrm{p}<0.01$ \\
\hline & ROOH* & $48,98 \pm 15,56$ & $27,11 \pm 5,82$ & $\mathrm{p}=0.02$ \\
\hline & PAOP** & $6,50 \pm 1,77$ & $600,12 \pm 97,63$ & $\mathrm{p}<0.01$ \\
\hline
\end{tabular}

Los valores representan el valor medio \pm la desviación estándar (DE) de los resultados experimentales en líquido seminal. * $\mu \mathrm{M} / \mathrm{mg}$ Proteínas, $* * \mu \mathrm{M}$ de cloramina T/mg proteínas

En el caso de la determinación de los biomarcadores de estrés oxidativo en el Lisado de espermatozoides, los resultados mostraron igualmente diferencias significativas $(\mathrm{p}<0.05)$ de los marcadores de daño celular en relación al grupo control de pacientes sanos con fertilidad probada con una $\mathrm{p}<0.01$ en los 3 marcadores de daño (Tabla 2).

Tabla 2. Indicadores del ambiente redox en Lisado de Espermatozoides

\begin{tabular}{|c|c|c|c|c|}
\hline \multicolumn{2}{|c|}{ Biomarcador } & Controles & $\begin{array}{c}\text { Pacientes en } \\
\text { estudio }\end{array}$ & $\begin{array}{l}\text { Test de U de } \\
\text { Mann-Whitney }\end{array}$ \\
\hline \multirow[t]{3}{*}{ Daño } & MDA & $2,15 \pm 0,21$ & $7,98 \pm 3,73$ & $\mathrm{p}<0.01$ \\
\hline & $\mathrm{ROOH}$ & $221,74 \pm 50,39$ & $82,20 \pm 23,74$ & $\mathrm{p}<0.01$ \\
\hline & PAOP & $3,10 \pm 0,87$ & $111,36 \pm 36,65$ & $\mathrm{p}<0.01$ \\
\hline
\end{tabular}

Los valores representan el valor medio \pm la desviación estándar (DE) de los resultados experimentales en lisado de espermatozoides. $* \mu \mathrm{M} / \mathrm{mg}$ Proteínas, $* * \mu \mathrm{M}$ de cloramina T/mg proteínas

Teniendo en cuenta las diferencias significativas apreciadas en las determinaciones realizadas, podemos deducir que estos pacientes presentan un desbalance de su estado redox, ya que hemos encontrado un alto grado de daño oxidativo a las biomoléculas en todas las muestras seminales tanto de LS como de LE de los pacientes analizados comparados con el grupo control. 
Como parte de este trabajo, se realizó además cuantificación de los indicadores del estado redox en los medios de cultivo a las 24 y 72 horas con el fin de correlacionarlos con el estado redox seminal.

\begin{tabular}{|c|c|c|c|}
\hline \multicolumn{2}{|c|}{ Biomarcador } & $\begin{array}{l}\text { Medio de Cultivo del } \\
\text { cigoto }\end{array}$ & $\begin{array}{l}\text { Medio de cultivo del } \\
\text { embrión }\end{array}$ \\
\hline \multirow[t]{3}{*}{ Daño } & MDA & $3 \pm 0.87$ & $2.90 \pm 1.83$ \\
\hline & $\mathrm{ROOH}$ & $4.32 \pm 1.37$ & $22.99 \pm 3.52$ \\
\hline & PAOP & $2.18 \pm 1.65$ & $7.29 \pm 3.88$ \\
\hline
\end{tabular}

Los valores representan el valor medio \pm la desviación estándar (DE) de los resultados experimentales en medios de cultivo embrionarios. ${ }^{*} \mu \mathrm{M} / \mathrm{mg}$ Proteínas, ${ }^{* *} \mu \mathrm{M}$ de cloramina $\mathrm{T} / \mathrm{mg}$ proteínas

Dado que el valor de p fue menor de 0.05 con un coeficiente de correlación de 0.634 (relación de moderada a fuerte), podemos plantear que se encontró correlación directa y estadísticamente significativa entre los productos avanzados de la oxidación a proteínas (PAOP) en Lisado de espermatozoides y medio de cultivo embrionario a las 24 horas (cigoto). De lo anterior se infiere que la presencia de estrés oxidativo en los gametos masculinos pudiera estar afectando la calidad embrionaria pues es precisamente en esta etapa embrionaria cuando luego de haber ocurrido la fecundación del ovocito, se produce la meiosis con el desempaquetamiento de la cromatina del ADN paterno.

Tabla 4. Correlación por R. de Spearman de PAOP en Lisado de Espermatozoides y
medio de cultivo embrionario de 24 horas
\begin{tabular}{|l|l|l|}
\hline & \multicolumn{1}{l}{$\begin{array}{l}\text { Coeficiente } \\
\text { correlación }\end{array}$} & EPAOP \\
\hline PAOP24 & $634^{*}$ \\
\hline Spearman's rho & Sig. (2-tailed) &, 027 \\
\hline & N & 15 \\
\hline
\end{tabular}

Los valores demuestran que existe una correlación moderada entre ambos parámetros para $\mathrm{p}<0.05$ con un $95 \%$ de nivel de confianza.

Los espermatozoides pueden generar niveles bajos de especies reactivas de oxígeno (ERO) las cuales participan en el proceso de capacitación y culminan en la fertilización, además de constituir uno de los mecanismos de defensa del organismo durante una infección, ya que causan la lisis bacteriana. Sin embargo, se ha demostrado que la producción en exceso produce daño a los organismos vivos por el EO.

El estrés oxidativo puede ser definido como la exposición de la materia viva a diversas fuentes que producen una ruptura del equilibrio que debe existir entre las sustancias o factores prooxidantes y los mecanismos antioxidantes encargados de eliminar dichas especies químicas, ya sea por un déficit de estas defensas o por un incremento exagerado de la producción de especies reactivas. Todo esto trae como consecuencia alteraciones de la relación estructura-función en cualquier órgano, sistema o grupo celular especializado; por lo tanto se reconoce como mecanismo general de daño 
celular. Se ha asociado el estrés oxidativo con alteraciones en la movilidad espermática, principalmente como resultado de la peroxidación lipídica y el agotamiento de los niveles de ATP. Altos niveles de actividad redox provocado por los espermatozoides ha sido relacionado con la inhibición de la reacción acrosómica y de la fusión esperma-oocito. Las ERO se caracterizan por reaccionar muy rápidamente con la mayoría de los compuestos orgánicos y comienzan una serie de reacciones en cadena que modifican la estructura de algunas moléculas biológicas, particularmente de aquellas que poseen un alto contenido de ácidos grasos poli-insaturados.

Los fosfolípidos (FL) de las células espermáticas son mayoritariamente ácidos grasos Poliinsaturados (AGPI) de cadena larga pertenecientes a las series n-3 y n-6 cuyas proporciones varían según la especie. (de La Rochebrochard, Quelen, Peikrishvili, Guibert, Bouyer, 2008) El alto grado de insaturación de los FL contribuye al movimiento celular y metabolismo lipídico, además confiere suficiente fluidez a la membrana plasmática del espermatozoide necesaria para los procesos de fusión con el óvulo. Niveles altos de radicales libres (RL) pueden aumentar la permeabilidad de la membrana plasmática del espermatozoide, causando diversas anormalidades en la morfología espermática alterando así la fertilidad masculina. Un aumento en los niveles de RL sugiere un alto estrés oxidativo y puede inhibir la acción de reacciones enzimáticas reguladoras, tales como la conversión a través de la catalasa de estos RL a agua, o alternativamente una inherente disminución en la expresión de sistemas enzimáticos. (Martínez, 2011)

Estos pacientes presentan parámetros normales de calidad seminal por el espermograma, por lo que si bien no habían podido concebir, no eran considerados como infértiles. El análisis de los marcadores que miden daño oxidativo demuestra otro resultado, ya que hemos encontrado valores elevados, fundamentalmente de Malonilaldehído (MDA) y los Productos Avanzados de la Oxidación de Proteínas (PAOP), resultados parecidos a los que obtuvo Mallok (2011) con iguales técnicas en pacientes infértiles.

A la hora de medir el daño oxidativo en las proteínas una herramienta experimental de gran utilidad es la cuantificación de productos avanzados de la oxidación de proteínas (PAOP). Estos compuestos son el resultado del entrecruzamiento, fragmentación y agregación de estas moléculas. Es conocido que los PAOP están relacionados con los procesos inflamatorios que tienen lugar bajo condiciones de EO y se forman fundamentalmente por la acción de la enzima mieloperoxidasa, presente solamente en monocitos activados. Esta enzima al ser activada genera grandes cantidades de ácido hipocloroso (HOCl), una ERO altamente oxidante. (Martínez, 2011) Los PAOP aparecen como marcadores del estrés oxidativo asociados a la uremia y otros mediadores inflamatorios capaces de amplificar la activación de monocitos. (Tesarik, 1999)

El proceso de Perioxidación Lipídica (POL), el cual también da como resultado la producción de radicales libres, es el mejor conocido de los daños mediados por ERO. El MDA es el producto de la POL, mejor estudiado. Este aldehído es una molécula tóxica que interactúa con el DNA y proteínas y a menudo es referido como mutagénico. El incremento de la POL se considera 
como una importante y esencial causa de la iniciación del estrés oxidativo relacionado con el daño a varios tejidos, la muerte celular y la progresión adicional de muchas enfermedades agudas y crónicas, como comprobó Agarwal (2008) en estudios realizados a pacientes con infertilidad tanto masculina como femenina. Las moléculas aldehídicas (MDA y 4-Hidroxialquenales), generadas durante la peroxidación lipídica, se han implicado como agentes causales en procesos citotóxicos iniciados por la exposición de los sistemas biológicos a agentes oxidantes. Estos aldehídos son considerados como mediadores terminales de los efectos tóxicos, provocados por estrés oxidativo, en materiales biológicos.

Durante la concepción natural o la fertilización in vitro (FIV) de rutina, el daño oxidativo a la membrana de los espermatozoides por lo general bloquea la fertilización y previene la creación de un embrión con daño de ADN Paternal que pudiera causar deleciones, mutaciones, y otros efectos genéticos letales.

En el caso del embrión diferentes estudios como el que realizó Tremellen (2013) plantean que puede producir niveles altos de ERO como consecuencia de la actividad de la enzima xantina y del metabolismo mitocondrial. El estado redox fisiológico es de vital importancia en el desarrollo embrionario, pero la superproducción de ERO puede ser perjudicial para su desarrollo. Las condiciones habituales de cultivo embrionario in vitro resultan en una producción excesiva de ERO y estrés oxidativo que puede comprometer el desarrollo embrionario antes de su implantación en el endometrio.

Podemos concluir que la totalidad de los indicadores redox de daño seminal analizado se encuentran elevados en los pacientes normozoospérmicos cuyas parejas fueron sometidas a fecundación in vitro en relación con los controles fértiles, lo cual sugiere que los pacientes normozoospérmicos que concurren a las consultas de FIV presentan alteraciones de la capacidad fecundante por estrés oxidativo. Los resultados además sugieren, que existe estrés oxidativo en los medios de cultivo embrionario que pudiera estar relacionado con el factor masculino, lo cual influye en las bajas tasas de embarazo por estas técnicas.

\section{REFERENCIAS BIBLIOGRÁFICAS}

Mallok, Akel, Martínez-Sánchez, Gregorio, Flores-Sánchez, Rosa María, \& Alonso-Rodríguez, Celia Ángela. (2011). Relación entre indicadores clínicos del espermograma y variables redox en infertilidad masculina. Revista Cubana de Farmacia, 45(3), 361-379.

Agarwal A, Said TM, Bedaiwy MA, Banerjee J, Alvarez JG. (2006). Oxidative stress in an assisted reproductive techniques setting. Fertil Steril, 86(3), 503-12.

Agarwal, A., Gupta, S., \& Sharma, R. K. (2005). Role of oxidative stress in female reproduction. Reproductive Biology and Endocrinology: RB\&E, 3, 28. http://doi.org/10.1186/1477-7827-3-28.

Tremellen, K. (2008). Oxidative stress and male infertility-a clinical pers- 
pective. Human reproduction update, 14(3), 243-258

Tremellen K, Miari G, Froiland D, Thompson J. (2007). A randomised control trial examining the effect of an antioxidant (Menevit) on pregnancy outcome during IVF-ICSI treatment. Australian and New Zealand Journal of Obstetrics and Gynaecology. 47:216-221.

Vicenta Paparella, C., Pavesi, A. B., Feldman, R. N., \& Bouvet, B. R. (2015). Importancia de la evaluación del estrés oxidativo en el semen humano. Archivos de Medicina Interna, 37(1), 7-14.

De Jonge C. (2005) Biological basis for human capacitation. Hum Reprod. 11:205-14.

Nicolich A, Lafuente R, López G, García-Peiró A, Brassesco M. (2013). Análisis del estrés oxidativo en el eyaculado mediante la determinación del anión superóxido. Revista de embriología clínica y biología de la reproducción. 18(1): 15-22

Gallardo- Montoya JM. (2007). Evaluación del sistema antioxidante en el semen normal. Rev Invest Clin. 59(1): 42- 47.

Alba LE, Monzón G, Peláez LA, Quintero Y. (2000). Papel del estrés oxidativo en la infertilidad masculina. Rev Cubana Invest Biomed; 19:202-5.

Agarwal A, Cocuzza M, Abdelrazik H, Sharma. (2008). Oxidative stress measurement in patients with male or female factors infertility. Handbook of Chemiluminescent Methods in Oxidative Stress Assessment. 195-218.

Delgado Roche L. (2012). Técnicas Analíticas para el Diagnóstico Redox. Editorial Académica Española.

de La Rochebrochard, E., Quelen, C., Peikrishvili, R., Guibert, J., \& Bouyer, J. (2009). Long-term outcome of parenthood project during in vitro fertilization and after discontinuation of unsuccessful in vitro fertilization. Fertility and sterility, 92(1), 149-156.

Martínez G. (2011). Ambiente antioxidante/ pro-oxidante: Su impacto médico. Ediz. spagnola

Tesarik, J., \& Greco, E. (1999). The probability of abnormal preimplantation development can be predicted by a single static observation on pronuclear stage morphology. Human Reproduction, 14(5), 1318-1323.

\section{Cumbres}

